\title{
APPROACHES TO THE ACCOUNTING OF TANGIBLE FIXED ASSETS IN PUBLIC INSTITUTIONS IN ROMANIA AND IN THE MILITARY IN THE LIGHT OF THE REQUIREMENTS OF INTERNATIONAL PUBLIC SECTOR ACCOUNTING STANDARDS (IPSAS)
}

\author{
Dumitru NICA \\ "Carol I" National Defence University, Bucharest, Romania \\ nicadumitru_aism@yahoo.com \\ Nicu Elinor BESTELIU \\ "Cantacuzino" National Military - Medical Institute \\ for Research and Development Bucharest, Romania \\ besteliu@gmail.com
}

\begin{abstract}
Accounting for tangible fixed assets is a very important part of the accounting of public institutions, because these types of assets have a very large share and come in a variety of forms in public entities of different sizes and profiles, without which they would not could fulfil the missions for which they were created. The issue of accounting for these assets according to national regulations has been proposed to highlight it by comparison with international regulations represented by accounting standards for the public sector. In addition to the significant progress made since 2005 in aligning public accounting in the area of tangible fixed assets with that of the international standard (IPSAS - 17), we have found that there are provisions that have not been implemented for various reasons. Therefore, based on the research of the specialized literature, personal experiences and a survey conducted by us among professional accountants in the army, we have identified some possible solutions to continue the process of implementing this international standard, opinions and solutions that we present at the end of this article.
\end{abstract}

KEYWORDS: tangible fixed assets, patrimony assets, property, plant and equipment, fair value, depreciation

\section{Introduction}

Accounting for tangible fixed assets or property, plant and equipment is an extremely important component of accounting for assets in public institutions, including the army. The structure of these assets is very diverse, and the value of most of them is remarkable, compared to other assets in public institutions.
The alignment of the accounting and reflection system in the financial statements of these assets in the Romanian legislation with the requirements in the field of the international profile standard (IPSAS - 17) represented and constitutes a major concern of the national regulator. We found, examining the specialized literature and research, that important 
progress has been made in the process of convergence of Romanian regulations with those of this international standard, but there are still aspects that need to be assimilated from it. Based on our own experience in accounting and a questionnaire applied to a significant number of professional accountants in the army, we have identified a few other issues that can be taken over and agreed in our legislation with the requirements of IPSAS -17 .

\section{Methodology}

The article aims to highlight the aspects that were taken over in the Romanian public accounting about the tangible fixed assets from IPSAS - 17, what aspects were not taken over and for what reasons and what perspectives exist for them to be fully assimilated from the mentioned standard. The article was written based on two methodologies:

- a review of the specialized literature and research undertaken so far by various professionals and specialists in the field of tangible fixed assets in public institutions;

- own research conducted on the basis of a questionnaire applied to a significant number of professional accountants in the army and capitalized in our research.

\section{Fundamental Aspects regarding} the Accounting of Tangible Fixed Assets in Public Institutions in Romania

Tangible fixed assets or tangible noncurrent assets (according to national public sector accounting legislation) are part of the broader component of assets, called noncurrent assets. Non-current assets include three categories of fixed assets, namely:

1) intangible fixed assets; 2) tangible fixed assets; 3) fixed financial assets.

Non-current fixed assets are components of assets held by public institutions for their long-term use. In this article we will focus only on tangible fixed assets.
A tangible fixed asset, according to OMPF no. 1917/2005 (Ministry of Public Finance, 2005), as subsequently amended and supplemented, is the object or complex of objects that are used as such and that cumulatively meet two conditions:

1) have a value higher than the limit value decided by decision of government;

2) have a natural duration of use of more than one year.

These assets have the following characteristics:

1) they are owned by a public institution for use in its own production of goods or in the provision of services, for rent or use for administrative purposes; 2) are used for a period of more than one year; 3) have a value higher than the limit established by the legal regulations in force.

These assets, in turn, include: 1) lands and landscaping; 2) constructions; 3) technical installations, means of transport, animals and plantations; 4) various components of furniture, office equipment, systems for the protection of various human and material values and other types of tangible assets not included in the categories listed above; 5) other assets belonging to the state; 6) advances for suppliers of tangible fixed assets; 7) tangible fixed assets under construction.

Specific to public institutions is the assimilation in the category of tangible fixed assets and the following assets: 1) heritage assets (as is the case with the following types of assets: buildings and monuments of a historical nature; lands with archaeological vestiges; conservation areas of different national values; natural reservations); 2) museum values, art objects and exhibitions; 3) books in libraries; 4) animals and birds for breeding; 5) specialized military equipment; 6) infrastructure assets.

Heritage assets are assets with a cultural, historical or environmental meaning and are characterized by a number of features such as: a) it is unlikely that 
their cultural, educational, historical or environmental value will be fully expressed in a financial form based only on market price; b) legal or statutory obligations may impose severe prohibitions or restrictions on their trading; c) they are often irreplaceable, and their value may increase over time, even if their physical condition depreciates; d) estimating their useful life can be difficult, sometimes reaching hundreds of years.

Infrastructure assets have either one or all of the following characteristics: 1) they belong to a system or network; 2) by nature they are specialized and have no alternative uses; 3) cannot be spatially displaced; 4) may be subject to constraints on assignment to other entities. This category of assets includes: road networks; sewerage systems; water, electricity, gas supply systems; telecommunications networks (International Public Sector Accounting Standards Board, 2021, pp. 532-533).

The category of other state assets includes deposits, uncultivated biological resources, and water reserves.

According to Government Ordinance no. 81/2003 (Government of Romania, 2003) with subsequent amendments and completions, are not considered tangible fixed assets: 1) motors, appliances and other subassemblies of tangible fixed assets, purchased for the purpose of replacing used components during repairs of any kind, which does not change the initial technical parameters of the tangible fixed asset; 2) special tools, instruments and devices, regardless of their value and normal duration of use; 3) temporary constructions and installations; 4) animals which have not fulfilled the conditions for being transferred to adult animals, fattening animals, bee colonies, except for breeding animals; 5) forests; 6) prototypes, as long as they serve as a model for the execution of series production, including zero series or which are subjected to tests for approval by the manufacturer;
7) protective and working equipment, special clothing and bed accessories, regardless of their value and duration of use.

Land accounting is kept separately for: land and land improvements. In analytical accounting, land can be highlighted by the following groups: agricultural land, forestry land, land without construction, land with deposits, land with construction and others.

Landscaping includes works such as: connection to the power supply system, access works, fencing and the like. According to the law, the lands are not subject to depreciation, but the land improvements are depreciated for a period of 10 years.

The constructions are highlighted by groups, subgroups, classes and subclasses, according to the Catalogue on fixed assets, the updated form, adopted by government decisions (Government of Romania, 2004 and 2008).

Fixed assets of the nature of technical installations, means of transport, animals and plantations as well as those in the category of furniture, office equipment, equipment for the protection of various human and material values and other tangible assets are highlighted by groups, subgroups, classes and subclasses, according to the same catalogue mentioned above.

There are recorded the advances granted to suppliers of tangible fixed assets as well as tangible fixed assets in progress, which represent unfinished investment work until the end of the period, carried out on its own account or in the enterprise. They are valued at production cost or acquisition cost, as appropriate. Tangible fixed assets in progress or execution are highlighted in the category of fixed assets upon completion after their receipt, entry into service or commissioning, as appropriate. 
Other state assets such as mineral resources located in the country, in the basement and on the continental shelf in the economic zone of Romania in the Black Sea, delimited according to the principles of international law and regulations signed by conventions and by our country are the exclusive object of public property and belong to the Romanian state.

Tangible fixed assets are recorded in the accounts at the time of the transfer of ownership for those purchased for consideration or on the date of preparation of documents for those built or produced by the institution, respectively received free of charge (Ministry of Public Finance, 2005).

Fixed assets must be initially valued at the following values: 1) at acquisition cost, for those purchased for consideration; 2) at the cost of production, for those built or produced by effort and with own resources by the institution; 3) the fair value for those obtained free of charge (such as donations, sponsorships, etc.).

The significance of the 3 types of values mentioned above is as follows: the acquisition cost is used for new fixed assets, purchased from third parties; this cost includes the price at which the good is purchased, plus the cost of transport, other non-deductible taxes and expenses incurred until the good is put into service; the production cost is used for the fixed assets obtained by the institution under its own management; this cost consists of the sum of the expenses incurred by the institution for making the investments; the fair value is used for the following categories of assets: a) tangible fixed assets entered into the institution through donations, free of charge; b) tangible fixed assets entered through inventory surpluses; c) fixed assets resulting from the dismantling of other fixed assets; d) those fixed assets found to be missing from the inventory.

The fair value of such assets is determined on the basis of valuations carried out by specialized certified assessors in real estate or movable property and must be approved by the authorizing officer.

According to Law no. 213/1998 (Parliament of Romania, 1998), the goods that enter the state patrimony are divided into goods that make up the public domain of the state and goods that make up its private domain.

The goods in the public domain of the state are the goods of interest and public use and over which the state exercises its possession, use and disposition. The goods from this group can be acquired by the state in the following ways: 1) naturally; 2) through public procurement; 3) by expropriation for utility reasons; 4) by donation or bequests admitted by the Government, by the county council or by the local council; 5) by transferring some goods from the private domain of the state or of the administrative-territorial units in their public domain, for the cause of public use; 6) other ways established by law. These assets are not subject to depreciation.

The goods in the private domain of the central or local state entities include goods that are in their property and that are not part of the public domain. These assets are subject to depreciation, unlike those in the public domain of state entities, which are not depreciated.

Tangible fixed assets can also enter the institution through: 1) the endowment performed by the hierarchically superior authorizing officer; 2) transfer from other public institutions; 3) donations made by third parties, natural or legal persons.

A very important operation is the valuation of tangible fixed assets after their initial recognition. Subsequent expenses incurred on tangible fixed assets are added to the cost of these assets, if two conditions are met: 1) they have the effect of improving performance over the initially established functional parameters; 2) obtaining future economic benefits can be achieved either directly, by increasing revenues or the 
potential of services provided, or indirectly by reducing maintenance and operating costs.

In the balance sheet, tangible fixed assets are reflected in the entry value, less accumulated value adjustments, respectively accumulated depreciation and accumulated adjustments for impairment loss. Depreciation of these types of assets is recorded in the accounts on a monthly basis, starting with the month following the commissioning or commissioning of these assets.

Public institutions depreciate tangible fixed assets using the linear depreciation method.

The following types of tangible fixed assets are not depreciated: 1) assets belonging to the public domain of state entities, including investments made in them; 2) tangible fixed assets from the management of public services of local interest that carry out activities of an economic nature, whose physical and moral wear and tear are recovered by tariff or price; 3) tangible fixed assets in conservation; 4) assets from the category of mobilization reserves that are registered in the accounting as tangible fixed assets; 5) assets in the form of lakes, ponds that are not the result of an investment; 6) lands; 7) the goods from the national cultural patrimony; 8) goods of the nature of armament and fighting technique.

Linear depreciation consists in the uniform inclusion in the expenses of public institutions of fixed amounts, established in proportion to the number of years of the normal duration of use of the fixed asset. Linear depreciation is calculated by applying the depreciation rate to the input value of fixed assets.

Our current legislation does not allow the use for intangible and tangible fixed assets other than the straight-line method and no other depreciation methods enshrined in the specialized literature (digressive, accelerated, etc.).
The decommissioning of tangible fixed assets is done with the approval of the main or secondary authorizing officer, depending on the subordination of public institutions.

Impairment of tangible fixed assets may occur in the following situations: 1) physical damage; 2) when the cessation takes place or the cessation of the request or need for services provided by such assets takes place; 3) when the good of this kind becomes unusable or must be transferred; 4) the existence of a decision to stop the construction of the respective asset, before its completion or commissioning; 5) performance in providing services lower than expected; 6) the existence of changes in technology or legislation in the field.

If we refer to the revaluation of such assets, the following regulations must be specified. The tangible fixed assets to be revalued are inventoried by an inventory commission appointed by the authorizing officer, in accordance with the provisions of OMPF no. 2861/2009 (Ministry of Public Finance, 2009) regarding the organization and inventory of items such as assets, liabilities and equity.

The following tangible fixed assets are not revalued: 1) those that entered in the patrimony during the year in which this operation is carried out and were recorded in the accounting at acquisition, production cost or at fair value, as the case may be; 2) those that at the date of the revaluation have a normal expired operating time; 3 ) those that are in conservation or that are part of the mobilization reserves and are recorded in the accounts as such assets; 4) for which the documents were drawn up, but the legal decommissioning approvals were not obtained and which were not dismantled, demolished or dismantled; 5) in progress.

Of course, there are other issues that would have stood out, but we consider that they were a priority and of great interest for what we set out to do in this article. 
4. Main Characteristics of IPSAS - 17 - Tangible Fixed Assets regarding the Accounting of these Assets and Aspects Taken from this Standard in the Romanian Public Accounting

In this part of the article, we set out to highlight the major concepts and coordinates inserted in this IPSAS - 17, the similarities, but especially the differences that separate national regulations from the provisions of this standard and what could be done for the almost complete implementation of this standard in Romanian public accounting.

A first aspect that we bring to attention from IPSAS - 17 is the definition of property, plant and equipment. According to this standard, such fixed assets are held for the purpose of their use in the manufacture or supply of goods or services, to be leased to third parties or for administrative use and are intended to be used for several reporting periods.

According to the O.M.P.F. no. 1917/ 2005 (Ministry of Public Finance, 2005), with subsequent amendments and completions, these assets represent the object or complex of objects that are used as such and that cumulatively meet two specific conditions: the input value is higher than the limit established by government decision; they have a normal duration of use over one year. It can be observed that in the specific Romanian legislation, this definition of tangible fixed assets represented an implicit but partial takeover.

Another concept that we bring to your attention is the patrimony assets, which in IPSAS-17 represent a series of features that we present below. These assets are so named because of their cultural, historical or environmental significance.

At the same time, these assets often have certain characteristics that we list below: a) their value, which consists in cultural, environmental, educational and historical parameters, is very unlikely to be fully reflected in financial terms, taking into account only the market price of such assets; b) requirements of a legal and/or statutory nature may impose severe prohibitions or restrictions related to their sale by sale; c) they are often irreplaceable with similar ones, and their value may increase over time, even if their physical condition deteriorates instead of consolidating; d) estimating their useful life may be difficult or even impossible to determine, in some cases, this can reach several hundred years.

According to the national normative act in the field of public accounting, the patrimony assets are goods that by their nature are of national use or interest. These types of assets are part of the public property of the state and bring together the following types of goods: a) the riches of any kind of subsoil, in a state of deposit; b) national parks; nature reserves and nature monuments; c) statues and monuments declared by the competent authorities as being of national public interest; d) historical and archaeological ensembles and sites; e) museums, art collections declared of national public interest, etc. From this comparative analysis it results that in the Romanian legislation this concept was taken over in an explicit manner.

A class of property, plant and equipment represents, in the IPSAS - 17 approach, a set or grouping of assets of a similar nature or function in the entity's operations, which is presented as a single, separate item for the purpose of presenting useful information in situations financial. For such a concept we do not have a similar approach in the profile accounting legislation represented by O.M.P.F. no. 1917/ 2005 (Ministry of Public Finance, 2005), with subsequent amendments and completions.

According to IPSAS - 17, the carrying amount of these assets is the value at which an asset is recognized after deducting depreciation and accumulated impairment 
losses, while in national accounting legislation the same value of these assets is that recorded in the accounts at the date of entry in the public institution of that asset.

Another concept for which there are different approaches in IPSAS - 17 and in Romanian legislation is the value subject to depreciation for property, plant and equipment. In the mentioned international standard, this value is the cost of an asset or a similar value that replaces the cost, minus the residual value of the asset, while in the Romanian legislator the same value is the book value of the asset to be recorded systematically administered over its useful life, so the approaches are quite different.

Next, we will mention five concepts for which in the Romanian legislation we do not have any similar or different concept. We refer to the following concepts: the specific or own value for the entity; recoverable amount; recoverable value of services; residual value; depreciation.

The specific or own value of the entity is the present value of the cash flows that an entity expects to derive from the continuing use, without interruption, of an asset of the nature of property, plant and equipment and from its disposal at the end of its useful life or the amount that the entity expects to bear when settling a debt related to this type of asset.

The recoverable value of such an invoice is the higher of the fair value of a cash-generating asset less costs to sell and its value in use.

In turn, the recoverable value of services is the higher of the fair value of an asset that generates non-cash flows from which the costs of selling and its value in use are deducted.

The residual value of such assets represents the estimated value that an entity would currently derive from the disposal of that asset, after deducting the estimated costs associated with the disposal, if that asset were already of the expected age and end of its useful life.
Depreciation of property, plant and equipment constitutes the systematic allocation of the depreciable value of such an asset over its useful life.

According to IPSAS - 17, various depreciation methods can be used for property, plant and equipment, which include: the straight - line method, the digressive depreciation method and the production unit method. The straight-line method of depreciation results in a constant expense over the useful life of such an asset if the residual value of the asset does not change. The digressive depreciation method results in a decreasing expense of this type over the useful life. The depreciation based on production unit method results in an expense determined based on the use or production expected to be obtained with that asset, which can be reliably determined. The entity shall select the depreciation method that most accurately reflects the expected rate of consumption of future economic benefits or service potential included in the asset for which the depreciation is calculated. The method of depreciation chosen must be applied consistently from one period to another, unless there is a change in the expected rate of consumption of those future economic benefits or the potential for services (International Public Sector Accounting Standards Board, 2021, pp. 541-542).

The Romanian legislation only allows the method of linear depreciation for tangible fixed assets under the management of public institutions.

The term referring to the useful life of an asset of the nature of tangible assets was taken from IPSAS - 17 in the Romanian legislation in an explicit manner. Thus in the standard this duration represents the period in which it is estimated that such an asset will be available for use in its specific activity by an entity or the number of production units or other units similar to those of production, which a public entity hopes to obtain from these types of assets. 
In the national legislation, the useful life of tangible fixed assets means the period during which it is estimated that the depreciated asset will be used, a period established according to the legal regulations (in this case the catalogue of fixed assets).

Following are 3 other concepts related to these types of fixed assets, which are defined in the standard to which we refer, but are not precisely configured conceptually in Romanian legislation. We consider the following terms: a loss on the impairment of a cash-generating asset; a loss on the impairment of an asset generating non-cash flows; infrastructure assets.

An impairment loss on a cashgenerating asset, according to IPSAS - 17, is the surplus by which the carrying amount of an asset on that invoice exceeds its recoverable amount. On the other hand, a loss on the impairment of an asset generating non-cash flows is, according to the same standard, the surplus by which the carrying amount of such an asset exceeds the recoverable amount of the services related to this type of goods.

Assets in the infrastructure category have, according to IPSAS - 17, in general, some or all of the following characteristics: a) they are part of a well-configured system or network; b) are very clearly specialized in the nature of assets and have no alternative uses; c) are spatially immovable; d) may be subject to constraints or restrictions when their assignment is intended.

Of course, there are other concepts and other terms related to tangible fixed assets (tangible fixed assets as they appear in the Romanian legislation) that were taken over from IPSAS - 17 more or less implicitly or explicitly, on which we do not detail, but we mention them here, namely: recognition of these assets (default takeover); initial costs (default takeover) and their subsequent costs (explicit and implicit takeover); recognition valuation of these assets (explicit takeover) (Rantrop \& Straton, October 2018).

Based on a questionnaire applied to a number of 78 professional accountants from entities of the Ministry of National Defence and their own opinions derived from personal experiences in the field, in connection with the extent to which this IPSAS - 17 standard could be even more deeply implemented in the Romanian profile legislation, we have advanced a series of opinions and suggestions that we present at the end of this article.

In our opinion, for the clearer definition of tangible fixed assets, according to IPSAS - 17, it is necessary, first of all, to specify in the definition in our legislation, what these types of assets are used for (production or supply of goods or services, rental for third parties or for administrative purposes).

Secondly, for these goods, the value for which tangible assets are considered should be increased, from 2,500 lei as it is now, to a minimum of 10,000 lei, in order to be truly more representative and easier to identify and evaluate.

In our opinion, for the clearer definition and identification of the patrimonial assets in the Romanian legislation, our competent ministry should take over the specifications from IPSAS - 17 regarding the specific characteristics of these assets (their value is unlikely to be expressed in full in financial terms by the market price; legal or statutory obligations may impose severe restrictions on the disposal of such assets).

The Romanian legislator should specify for tangible assets that their book value should be recognized and recorded not only when (at the entrance to public institutions), but also how, at what value (as specified in IPSAS - 17, that is, after deducting the accumulated impairment and the accumulated impairment losses). 
In our opinion, it should also be accepted in our legislation as methods of depreciation of these fixed assets in public institutions not only the linear, but also the digressive and production units (as presented as possibilities in IPSAS - 17).

A second aspect refers to the provision of depreciation through the 3 depreciation methods, not only for tangible assets in the private sphere of the state, but also for those in the public domain of this very important economic agent, for which the calculation of depreciation of any kind is not allowed (including for armament and combat equipment in military units).

In this way it could be reflected at a fairer value and more in line with the reality of such assets that hold a very large share in the wealth or patrimony of public institutions.

In order to determine the value to be depreciated for such tangible assets, the Romanian legislature should no longer take into account only the carrying value of each asset, recorded systematically over its useful life, but the cost of such an asset or other value that replace it, subtracting the residual value of that asset (as provided in IPSAS - 17).

In this context, we must mention how the residual value influences the annual depreciation of tangible fixed assets.

The residual value of an asset is the amount that the owner of that asset can expect to obtain if the asset is sold. The simplest is to estimate a residual value equal to 0 .

There are many types of fixed assets, most of them of small value, for which it can be estimated that after their use, there will be no residual value. This also simplifies the calculation of depreciation.

The most neutral solution to the problem is to compare it with the value of other similar assets traded on the market. However, this solution is applicable to common fixed assets: examples: used cars, computer technology, etc. and less for those with a higher degree of customization for a particular field.
The annual depreciation for the asset with an entry value of 100,000 lei and a residual value of 20,000 lei is calculated as follows: $(100,000$ lei entry value $-20,000$ lei residual value $) / 5$ years $=16,000$ lei.

According to our legislation, the useful life of a tangible fixed asset is the period of time during which it is estimated that the depreciated asset will be used. This period is recorded in a catalogue of fixed assets and includes a minimum and maximum range of years. Unfortunately, this catalogue does not keep up with the changes of these periods under the impact of the emergence of new tangible assets strongly influenced by the contemporary technical-scientific revolution.

We therefore consider that it would be appropriate to take up the approach of this issue in IPSAS - 17 according to which the useful life of a tangible fixed asset is the period in which it is hoped that such an asset will be available for use by an entity or the number of production units or other similar units that an entity expects to obtain from that asset.

Therefore, in our opinion, the duration of the current catalogue of fixed assets should be purely indicative, and at the annual inventory, for each property, plant and equipment, depending on its new physical condition, production units or other units of expected results to be achieved in the future, to be able to establish a new remaining period of operation of these assets and a new annual amortization.

In our opinion, the provision that exists in IPSAS - 17 should be introduced in the Romanian legislation, so that the valuations or revaluations of tangible assets should be made annually and not at a certain period of time (every 3 years, from 5 in 5 years or at other intervals, but not annually), to determine the fair value.

\section{Conclusion}

The current Romanian public accounting regarding tangible fixed assets has made important progress on the line of 
partial alignment with the international accounting standard related to such goods (IPSAS - 17), taking over almost identically or very similarly a number of concepts, terms or procedures used for these assets.

The differences that still separate the way of defining some terms and operations and their accounting are mainly related to the type of accounting chosen by the Romanian legislators in public institutions (the continental type of French inspiration) compared to the Anglo-Saxon one which is predominant in this international accounting standard.

The efforts made by the Romanian authorities to bring public accounting closer to the Anglo-Saxon one, in parallel with the possible acceptance of the increasingly frequent and justified opinions of some Romanian reference specialists to emphasize the implementation of IPSAS as a whole and of this IPSAS - 17, will certainly lead in a not-too-distant time horizon to the full implementation of this standard in the Romanian public accounting.

We hope that some of the opinions expressed by us in this article will constitute a basis for analysis in the process of finalizing the full implementation of this IPSAS - 17 in Romanian public accounting in the future.

\section{REFERENCES}

Government of Romania. (2003). Government Order no. 81/2003 on the revaluation and amortization of fixed assets in the patrimony of public institutions, with subsequent amendments and completions. The Official Gazette of Romania, Part I, no. 624 of August 31, 2003.

International Public Sector Accounting Standards Board. (2021). International Public Sector Accounting Standards (IPSAS). Volumes I and II, New York.

Ministry of Public Finance. (2005). OMPF no. 2861/2009 for the approval of the Norms regarding the organization and performance of the inventory of the elements of the nature of assets, debts and equity. The Official Gazette of Romania, Part I, no. 704 of October 20, 2009.

Parliament of Romania. (1998). Law no. 213 of November 17, 1998 on public property and its legal regime. The Official Gazette of Romania, Part I, no. 448 of November 24, 1998.

Popa, A.F. (2021). Contabilitatea altor tipuri de entități. Bucharest: CECCAR Publishing House.

Rantrop \& Straton, Advisor publication. (2018). "Contabilitate pentru instituții publice", "Politici contabile privind activele fixe corporale conform IPSAS - 17 - Imobilizări corporale" published in October. 